ISSN 2179-345X

Licenciado sob uma Licença Creative Commons

\title{
Compras coletivas e as lesividades na relação de consumo
}

\section{Collective purchasing and lesividades in the consumption}

\begin{abstract}
Antonio Baptista Gonçalves
Doutor e mestre em Filosofia do Direito pela Pontifícia Universidade Católica de São Paulo (PUC-SP), membro do Instituto Brasileiro de Direito Tributário, São Paulo, SP - Brasil, e-mail: antonio@antoniogoncalves.com
\end{abstract}

\section{Resumo}

A compra coletiva é uma nova modalidade de comércio eletrônico que afeta a relação de consumo e, como tal, deverá observar todos os regramentos e ditames do Código de Defesa do Consumidor. No entanto, o que se vê, na prática, é a lesividade ao consumidor por meio de uma série de problemas que variam desde o fornecimento do produto ou serviço até a presença de cláusulas abusivas e propagandas enganosas. Assim, analisar quais as responsabilidades tanto do fornecedor quanto do site de compra coletiva será o objeto deste artigo, inclusive para verificar a hipótese de lesividade à concorrência.

Palavras-chave: Compra coletiva. Responsabilidade objetiva. Abuso de direito. 


\section{Abstract}

The collective purchasing is a new type of commerce that affects the relationship of consumption and, therefore, should rules and observe all the precepts of the Code of Consumer Protection. However, what we see in practice is detrimental to the consumer through a series of problems ranging from the supply of the product or service to the presence of unfair and deceptive advertisements. Thus, analyzing the responsibilities of both the supplier and the place of purchase conference will be the subject of this article, including to verify the hypothesis harmful to competition.

Keywords: Collective purchasing. Strict liability. Abuse of law.

\section{Introdução}

A realidade da compra coletiva ainda é recente. No Código de Defesa do Consumidor não existe uma previsão legal para essa modalidade em específico. No mesmo sentido, também não há previsão no Código Civil.

Além de tratar de um grupo de consumidores temos a questão da venda eletrônica, isto é, o comércio eletrônico, que, igualmente, encontra pouca legislação sobre o tema. Assim, termos de fazer algumas construções para poder disciplinar o tema. Contudo, o importante é que se proteja a relação de consumos contra abusos e danos advindos da compra coletiva.

A ideia de compras coletivas corresponde a um site que age como intermediário entre o fornecedor e consumidor, propiciando elevados descontos, desde que um número fixo de pessoas compre o produto ofertado. E esses produtos possuem uma elevada variedade: perfumes, viagens, corridas de kart, shows, teatro, restaurantes, salões de beleza, centro de estética, etc.

Os problemas surgem quando o serviço não é prestado e no questionamento do preço em si, pois enseja a possibilidade de lesividade à concorrência na relação de consumo. 


\section{Conceito de compra coletiva}

A compra coletiva é conceituada como um sistema virtual de aquisição de um produto por um preço mais econômico que o proposto pelo mercado. Para tanto, se estabelece um número mínimo de pessoas que devem adquirir aquele produto ou serviço em um determinado período (usualmente são cem pessoas que possuem 24 horas para adquirir a oferta).

A relação de consumo somente se efetiva quando do aceite do consumidor para com o contrato de prestação de serviço. Caso seja exaurido o prazo sem que se tenha atingido o número mínimo, a venda se dissolve e os consumidores terão de ser ressarcidos.

\section{As condições de validade da compra coletiva}

Como já dito, é necessário haver um número mínimo de participantes, em geral, cem pessoas. Contudo, essas não são as únicas regras que devem ser observadas pelo consumidor. Também é necessário ter atenção com o prazo para o consumo da oferta, pois existe um período em que começa e termina o uso daquela compra.

Nos sites existe a possibilidade de reembolso, porém, na prática, o que se vê é o consumidor em contatos infindáveis com o Serviço de Atendimento ao Consumidor (SAC), sem qualquer tipo de solução jurídica ou quiçá econômica para a questão. Ademais, no mesmo problema incorre aquele que deseja cancelar o serviço, pois recai na dificuldade da ineficiência na prestação jurisdicional.

Em ambos os casos, o site de compra coletiva infringe o artigo 49 do CDC, como salienta Nelson Nery Júnior (2011, p. 41):

o Código consagra o direito de o consumidor arrepender-se e voltar atrás em declaração de vontade que haja manifestado celebrando relação jurídica de consumo. $O$ direito de arrependimento existe per se, 
sem que seja necessária qualquer justificativa do porquê da atitude do consumidor. Basta que o contrato de consumo tenha sido concluído fora do estabelecimento comercial para que incida, plenamente, o direito de o consumidor arrepender-se.

Sobre a compra coletiva, não existe a análise física da proposta, as condições são obscuras, imiscuídas no contrato de adesão que não é transparente. Logo, é devida, por entendimento extensivo, a obrigação de ressarcimento em caso de desistência do consumidor que se arrependeu da compra ou que não poderá usufruir do produto/serviço por motivos alheios.

Não pode o site de compra coletiva ludibriar o consumidor por meio do SAC, prometendo soluções que nunca aparecem ou se concretizam. Isso quando o consumidor consegue ser atendido, pois os números fornecidos tendem a dar sinal de ocupado continuamente. Portanto, se considera: ou as reclamações se avolumam ou os números possuem problemas. Começamos a crer na primeira possibilidade.

\section{O Direito Eletrônico e a previsão normativa na compra coletiva}

O Direito Eletrônico ainda não possui uma normatividade ou um conjunto normativo eficaz no Direito Pátrio, o que enseja o questionamento de validade acerca da compra coletiva, uma vez que o negócio é exclusivamente eletrônico.

O fato de um site intermediar um negócio jurídico em nada obsta a aplicação da legislação protetiva a todo e qualquer contrato, como se este fora em uma relação civil. De tal sorte que, a seara destinada a regular os comportamentos e as regras contratuais em si será a consumerista, pois se trata de uma prestação de serviço mediante contratação e pagamento. 


\section{O Código de Defesa do Consumidor e a normativização da compra coletiva}

De início, podemos equiparar o contrato de compra coletiva a todo e qualquer contrato de prestação de serviço; logo, sujeito às regras e condições do Código de Defesa do Consumidor.

Como afirma Maria Eugênia Finkelstein (2011, p. 221-222):

o desenvolvimento do comércio eletrônico traz à atenção de seu usuário o problema relacionado à proteção do consumidor nos contratos de consumo celebrados eletronicamente. Ao contrário do que se possa imaginar, o consumidor eletrônico não se encontra tão desamparado como poderá parecer à primeira vista. Isso se dá por dois motivos igualmente relevantes. O primeiro deles diz respeito à imediata aplicação do Código de Defesa do Consumidor aos contratos de consumo eletronicamente celebrados. [...] O segundo motivo diz respeito ao princípio geral da boa-fé que orienta nosso Direito como um todo, inclusive abrangendo as relações de consumo. Este princípio é, antes de tudo, um princípio de ordem moral, que deve orientar toda e qualquer relação humana. Significa que o Homem deve relacionar-se com outro Homem com sinceridade, lealdade e honestidade, de forma a não prejudicar os demais. Em sendo assim, o princípio geral da boa-fé possui aplicação tanto na celebração do contrato, como em sua execução e posteriormente.

Assim, mesmo na ausência de uma legislação para o comércio eletrônico, nada obsta que a prestação jurisdicional seja executada sob a égide do Código de Defesa do Consumidor.

No mesmo sentido, Carlos Roberto Gonçalves (2003, p. 117) diz:

crescem, a cada dia, os negócios celebrados por meio da Internet. Entretanto, o direito brasileiro não contém nenhuma norma específica sobre o comércio eletrônico, nem mesmo no Código de Defesa do Consumidor. [...] No estágio atual, a obrigação do empresário brasileiro que dele se vale para vender os seus produtos ou serviços, para com os consumidores, é a mesma que o referido diploma atribui aos fornecedores em geral. A transação eletrônica realizada entre brasileiros 
está, assim, sujeita aos mesmos princípios e regras aplicáveis aos demais contratos aqui celebrados.

No Direito brasileiro, o conceito basilar é a boa-fé, ou seja, ninguém celebra um negócio jurídico com a finalidade precípua de ludibriar terceiros, obter vantagem indevida. Assim, o Código Civil vigente prevê a boa-fé nos contratos, como a presunção de que todos são feitos de forma lícita e para que ambos tenham vantagens na transação. E o Código de Defesa do Consumidor segue a mesma linha doutrinária por meio do artigo 51, IV.

Em consonância com tal pensamento, então, é necessário estabelecer quem será o consumidor (art. $2^{\circ}$ ) e quem será o fornecedor (art. $3^{\circ}$ ).

Quanto ao consumidor não resta dúvida, pois, como disciplina o parágrafo único no artigo $2^{\circ}$ do $C D C$, será a coletividade que adquiriu o produto proposto para consumo pelo site de compra coletiva.

Já no tocante ao fornecedor, eis o problema: ao contrário do que os consumidores pensam não se trata do site de compra coletiva, uma vez que este apenas age como intermediário entre o produto ofertado por um fornecedor e a aquisição pelo consumidor, segundo sua própria interpretação. Isso faz com que estipulem cláusula expressa se eximindo de qualquer responsabilidade, por se tratar meramente de intermediário.

A consequência é que se o serviço não for prestado de forma correta quem deverá figurar no polo passivo de uma eventual ação? A resposta será o fornecedor e não o site. No entanto, esse não é nosso posicionamento e trataremos do tema um pouco mais adiante.

\section{Os requisitos de validade de um contrato de compra coletiva à luz do Direito Civil e do Direito do Consumidor}

Inspirados nos regramentos contratuais previstos no Código Civil, podemos deduzir a necessidade de alguns elementos para efetivar e conformar o contrato de compra coletiva como um contrato. 
Primeiro é necessário que exista e seja manifestada a vontade entre as partes. Nessa seara não resta dúvida, pois o objeto de venda está à inteira disposição do consumidor, ainda que de forma parcial, como trataremos mais adiante. De outro lado, o consumidor ao efetivar a compra também manifestou a sua vontade; logo, a bilateralidade das vontades se consuma.

Sobre o tema, Claudia Lima Marques (2005, p. 53) acentua:

como primeira aproximação ao estudo da concepção tradicional de contrato vamos examinar a definição do grande sistematizador do século XIX, Friedrich von Savigny, segundo a qual o contrato é a união de dois ou mais indivíduos para uma declaração de vontade em consenso, através da qual se define a relação jurídica entre estes.

Dessa definição podemos extrair também os demais elementos necessários para um contrato: o livre convencimento das partes, as partes serem capazes de direitos e obrigações, art. $4^{\circ}$, III, do CDC, ter um preço justo e um prazo estabelecido.

Todos esses elementos estão presentes na compra coletiva, como podemos ver: o produto está à disposição para ser comprado, existe uma descrição mínima das suas condições de validade, outrossim, temos ainda termos e condições da aplicabilidade e validade da relação que se estabelece a partir da compra do produto.

Ainda temos a questão do prazo estipulado para que o consumidor possa usufruir de sua compra; logo, não se trata de um contrato por prazo indeterminado. E, claro, não podemos deixar de mencionar o elemento vinculativo do próprio contrato, isto é, ao comprar o produto o consumidor se obriga a cumprir com as cláusulas previstas e, de outro lado, também tem direitos que devem ser respeitados pelo fornecedor.

Sendo assim, no plano teórico podemos dizer que se trata de um perfeito contrato de prestação de serviço, no qual o fornecedor se obriga a prestar um serviço em um prazo determinado e o consumidor se obriga a consumi-lo ou dele desfrutar mediante pagamento, em data igualmente limitada. 
Somada ainda a questão da boa-fé, temos uma relação contratual, apesar de virtual, equiparada à relação civil e consumerista contratual tradicional.

\section{Os problemas da compra coletiva}

Em uma primeira análise, aparentemente não existiriam problemas a serem elencados por parte da transação da compra coletiva, uma vez que os requisitos contratuais consoantes com o CDC estão presentes. Contudo, isso se reflete apenas em um olhar meramente superficial, pois os problemas surgem já na assunção e confecção do próprio contrato de prestação de serviço.

Como a maioria dos contratos de consumo, o contrato de compra coletiva é de adesão, isto é, não existe negociação das cláusulas entre as partes, ou se adere na integralidade ou não se firma o negócio.

Assim, o consumidor primeiro deve fazer o que a maioria já ignora: ler o contrato. Aqui reside o primeiro engano comum dos consumidores, o de que na compra coletiva, por se tratar de um contrato eletrônico, não existe, portanto, um contrato físico. De fato, fisicamente não existe um contrato, porém, este deve existir e ser disponibilizado no próprio site.

Depois, é preciso verificar, apesar de estarem presentes as cláusulas de adesão, se elas não ferem o artigo 51, IV. Isto é, se o contrato não possui as denominadas cláusulas abusivas. Essas cláusulas são aquelas que conferem uma vantagem excessiva e até mesmo indevida ao fornecedor em detrimento do consumidor, a parte hipossuficiente dessa relação de consumo. Assim, quando o contrato for considerado abusivo, ou tiver cláusulas nessa condição, poderá ser suscetível à nulidade do contrato e a indenização ao consumidor.

Outro problema deveras comum é a não devida transparência do contrato, com a explicação clara e cristalina das cláusulas nele contidas. Pode parece folclore, contudo não o é, são as famigeradas letras miúdas, 
isto é, a parte lesiva ao consumidor possui uma fonte de tamanho menor, justamente para dificultar a sua leitura da e, assim, ludibriar o consumidor.

Da mesma maneira, o produto da compra coletiva contém uma gama de falhas em sua publicidade. Portanto, fere diretamente o artigo $6^{\circ}$, III, do CDC. É muito comum nos sites de compra coletiva, sem a necessidade de nominar esse ou aquele, a oferta de pacote de viagem para uma cidade fora do Brasil. Na oferta consta o nome do hotel, informação de que a passagem aérea está inclusa e que o consumidor tem uma data limite para usufruir do pacote. À primeira vista não existem problemas, porém, nesse simples anúncio uma série de abusos e falhas contra a relação de consumo está presente:

1) não se sabe a distância do hotel em relação ao centro;

2) não se sabe o que a companhia aérea fará em caso de motivo de força maior, overbooking ou cancelamento sumário do voo, sem disponibilidade para o período previamente imposto pela compra coletiva;

3) não é informado ao consumidor que, se não for encontrada uma data disponível para a viagem, ele perderá a quantia paga, pois no mais das vezes as datas escolhidas já estão preenchidas;

4) sobre as vagas outro paradoxo, pois se cem pessoas compram os pacotes então é de se presumir que existam, no mínimo, cem datas ou horários disponíveis, senão haverá a lesividade consumada da relação contratual;

5) em nenhum lugar constam os dados exatos do fornecedor, como CNPJ, endereço, telefone para contato;

6) o contrato, em geral, é silente no tocante ao cancelamento;

7) não existe qualquer tipo de aviso ou multa por parte do site de compra coletiva no caso do serviço do fornecedor não ser adequado ou consoante com o ofertado.

Citamos aqui alguns parcos exemplos de como se mascarar a relação de consumo e lesar o consumidor ao mesmo tempo. O mesmo 
exercício pode ser feito para uma gama de outros produtos e serviços ofertados pelos sites de compra coletiva. Exatamente por isso, em matéria de jornal impresso de 22 de novembro de 2011, se demonstra que o Procon vem autuando alguns sites de compra coletiva.

A compra coletiva parece, em um primeiro momento, a oportunidade do hipossuficiente de ter acesso a bens materiais que não conseguiria pelas vias comuns. Assim, a compra coletiva se mostra de forma muito sedutora, porém, como veremos, o que se mostra de fato é a consumação de uma autêntica propaganda enganosa.

\section{A propaganda enganosa da compra coletiva}

O hipossuficiente que recebe a oferta de um produto advindo da compra coletiva não sabe, de fato, a real intenção do site em disponibilizar tal produto. A grande propaganda, de desconto e preço tão reduzidos, é resultado do elevado número de consumidores que irão adquirir o produto, portanto, a negociação se torna viável em decorrência direta da quantidade. E, por isso, quando o número de compradores não é atingido o negócio se torna inviável.

Em realidade, não é bem assim que se processa o lucro do site de compra coletiva, pois não é apenas na quantidade e na negociação que o dinheiro aparece. Esse site foi concebido e desenvolvido como forma de obter lucro a partir de produtos que não tinham uma saída imediata no mercado. Logo, se criara uma promoção a fim de incentivar os consumidores a "desencalhar" os produtos. E, evidentemente, uma comissão era para o site pela divulgação do produto e sua consequente venda.

Em um momento posterior, como a demanda começou a superar a oferta, os sites de compra coletiva abriram as oportunidades para que outros tipos de produtos e serviços fossem oferecidos, portanto, a prestação de serviços se abrangia.

No entanto, como funciona, de fato, o site de compra coletiva? O responsável pela compra recebe uma comissão em caso da venda 
coletiva e pela consequente oferta do produto e, além disso, igualmente recebe um percentual da venda coletiva.

Ademais, é uma ilusão ao consumidor dizer que o preço ofertado é muito menor que o real, pois, em alguns produtos, especialmente no quesito viagens, a negociação coletiva é mais cara que se o próprio consumidor negociar diretamente com o mesmo hotel e com a mesma companhia aérea cem passagens e hospedagens.

Contudo, nada disso é repassado ao consumidor e, ao se omitir dados importantes de um produto, das condições do estabelecimento ou da durabilidade do produto, o site incorre nos artigos 37 e 66 do CDC, configurando-se, portanto, a propaganda enganosa.

Outro erro provocado pelo site de compra coletiva é levar, erroneamente, o consumidor a crer que ele é o responsável, o garantidor da excelência da relação de prestação de serviços. Quando, em verdade, o site deixa claro nos contratos de adesão ser um mero intermediário, portanto, se eximindo de toda e qualquer responsabilidade.

Eis um exemplo típico de cláusula abusiva. Portanto, não pode o site simplesmente eximir-se de responsabilidade, como se não soubesse de nenhum tipo de vício por parte do fornecedor, quando, de fato, foi exatamente o site que disponibilizou as informações. No mais, foi ele que entrou em contato com o fornecedor; logo, deve sim figurar no polo passivo de uma ação de indenização.

\section{O abuso do poder econômico e a concorrência desleal da compra coletiva}

Agora, entraremos em seara complexa e conflituosa que envolve não apenas o consumidor, como, também, os demais fornecedores que não os dos sites de compra coletiva. Então, ainda na seara das abusividades e lesividades cometidas e perpetradas pelo site de compra coletiva, temos dois aspectos pouco conhecidos do público: o abuso do poder econômico e a concorrência desleal da compra coletiva. 
Afinal, se os fornecedores, de uma maneira geral, vendem o mesmo produto ou serviço com preços similares não há porque haver uma disparidade tão acentuada em relação ao site de compra coletiva. Ao reduzir o preço final para o consumidor, a concorrência está afetada em relação aos demais fornecedores que ofertam o mesmo produto ou serviço.

Configura-se, então, uma lesividade à proteção constitucional expressa da livre concorrência, por meio do art. 170, IV. E nesse aspecto devemos conceituar concorrência.

Segundo Armando Castelar Pinheiro e Jairo Saddi (2005, p. 355):

para que haja concorrência, é necessário que o mercado tenha um número suficientemente grande de produtores e consumidores de tamanhos não muito diferentes, agindo de forma independente. Isso faz com que nem vendedores nem compradores tenham poder de mercado, não sendo capazes de determinar, de forma unilateral ou coordenada, as condições com que bens e serviços são comercializados no mercado - em termos de preço, qualidade dos produtos e condições de venda, por exemplo.

E, como destaca Nelson Nazar (2009, p. 63), é necessário não confundir livre concorrência com abuso de poder ou concorrência desleal:

duas são as formas de concorrência repudiadas pelo direito: a concorrência desleal e o abuso de poder. A Constituição coíbe o abuso do poder econômico que vise à dominação dos mercados, à eliminação da concorrência e ao aumento arbitrário de lucros (Constituição Federal, art. $\left.173, \S 4^{\circ}\right)$. Os prejuízos à livre concorrência estão elencados na Lei n. 8.884/1194, em seu art. 20.

Por meio da baixa forçada do preço, o site de compra coletiva altera, artificialmente, o valor de mercado do produto ofertado, ocasionando, portanto, uma lesividade aos demais fornecedores.

Então, tratamos de três coisas distintas: quando os fornecedores concorrem entre si, dentro dos limites da lisura, assim, tem-se a concorrência; quando um fornecedor, ou um grupo de fornecedores, manipula o preço do serviço ou produto para, por conseguinte, dominar o mercado, 
então, temos a concorrência desleal; e a imposição de um preço por parte do fornecedor sem que o consumidor tenha possibilidade de flexibilização, portanto, configura o abuso do poder econômico.

Sobre abuso do poder econômico, Ricardo Hasson Sayeg (1995, p. 73) diz:

o consumidor, não possuindo ingerência sobre os bens de produção, bem como sobre a disposição dos bens ou serviços colocados no mercado, não tem o poder que o fornecedor isoladamente tem, de intervir da oferta e da procura existente entre ambos.

Assim, ao se tratar de concorrência, abuso de poder econômico e concorrência desleal, temos de submeter o tema à consonância do artigo $1^{\circ}$ da Lei n. 8.884, de 11 de junho de 1994.

Segundo José Geraldo Brito Filomeno, fica claro que a proteção e o incentivo às práticas leais de mercado interessam aos próprios fornecedores.

De tal sorte que podemos elencar as responsabilidades da concorrência desleal para os sites de compra coletiva, por meio do art. 20 da Lei n. 8.884/94:

Art. 20. Constituem infração da ordem econômica, independentemente de culpa, os atos sob qualquer forma manifestados, que tenham por objeto ou possam produzir os seguintes efeitos, ainda que não sejam alcançados:

I - limitar, falsear ou de qualquer forma prejudicar a livre concorrência ou a livre iniciativa;

II - dominar mercado relevante de bens ou serviços;

III - aumentar arbitrariamente os lucros;

IV - exercer de forma abusiva posição dominante.

$\S 1^{\circ}$ A conquista de mercado resultante de processo natural fundado na maior eficiência de agente econômico em relação a seus competidores não caracteriza o ilícito previsto no inciso II.

$\S 2^{\circ}$ Ocorre posição dominante quando uma empresa ou grupo de empresas controla parcela substancial de mercado relevante, como 
fornecedor, intermediário, adquirente ou financiador de um produto, serviço ou tecnologia a ele relativa.

O efeito é que a responsabilidade não é apenas da empresa que constitui o site de compra coletiva, mas, também, de seus sócios, como disciplina o artigo 16 da mesma lei.

É importante destacar que o abuso do poder econômico e a concorrência desleal, neste tema em específico, não ocasionam reflexos para os consumidores, porém afetam diretamente as relações de mercado entre os sites de compra coletiva e os demais fornecedores de produtos ou serviços similares. Contudo, com preços elevadamente diferentes e que não podem concorrer com as ofertas economicamente muito menos custosas da compra coletiva.

De tal sorte que o abuso de poder econômico pode e deve ser coibido, como salienta Nelson Nazar (2009, p. 79): "abuso de poder econômico é o comportamento de uma empresa ou grupo de empresas que utiliza seu poder de mercado para prejudicar a livre concorrência, por meio de condutas anticompetitivas".

Sobre o tema, como se trata de relação entre fornecedores, não há que se falar em Código de Defesa do Consumidor e sim das normas e regulamentações do Conselho Administrativo de Defesa Econômica (Cade), presente e previsto também na Lei n. 8.884/94, nos artigos $3^{\circ}$ e seguintes.

O principal elemento a ser protegido quando da configuração do abuso do poder econômico é a limitação do livre mercado e, por conseguinte, da concorrência. Quando existe uma fixação, um conluio de um grupo de empresas para reduzir o preço final de um produto ou serviço não há estímulo da concorrência e sim uma concorrência desleal.

\section{Das responsabilidades dos sites de compra coletiva}

Em que pese a previsão expressa na maioria dos contratos de compra coletiva de que o site de compra coletiva seja um mero 
intermediário e que a relação de consumo se processa diretamente entre o consumidor e o fornecedor do produto ou serviço, o nosso entendimento é de que a empresa de compra coletiva poderá, sim, figurar no polo passivo de uma ação de indenização por reparação de danos, por ter uma responsabilidade objetiva.

Sobre o tema, José Pires de Oliveira Dias e Patrícia Pontes Passarelli Prado (2011, p. 418) comentam:

a responsabilidade objetiva é divida em duas espécies, sendo uma a responsabilidade pelo fato do produto e do serviço - que deriva de danos causados pelo produto ou serviço, também denominados "acidentes de consumo", ou seja, qualquer acidente provocado por serviços ou produtos que causem danos ao consumidor -, e outra a responsabilidade por vícios dos produtos ou serviços - que se refere a fatos inerentes a vícios dos produtos ou serviços, que os tornem impróprios ou inadequados ao uso a que se destinavam originalmente.

De tal sorte que, em consonância com os artigos 12 a 17 do CDC, o fornecedor responde por responsabilidade objetiva, independentemente de culpa, pelos danos causados aos consumidores, por vícios de informação ou, ainda, por defeitos relativos à prestação do serviço.

Nelson Nery Junior e Rosa Maria de Andrade Nery (2011, p. 799), a esse respeito, defendem:

a responsabilidade civil no $C D C$ se assenta no risco da atividade do fornecedor em face do consumidor, tanto pelo aspecto contratual quanto pelo aspecto extracontratual. Tanto a responsabilidade pelos acidentes de consumo como a decorrente dos vícios do produto ou serviço (CDC 12, 14, 18 e 19) se estribam na teoria objetiva. O fundamento do dever de indenizar, aqui, é o risco da atividade: por isso a responsabilidade objetiva se aplica a todas as hipóteses decorrentes de danos experimentados pelo consumidor em decorrência de relação jurídica de consumo.

No mesmo sentido, Carlos Roberto Gonçalves (2003, p. 389) diz: 
o Código de Defesa do Consumidor, atento a esses novos rumos da responsabilidade civil, também consagrou a responsabilidade objetiva do fornecedor, tendo em vista especialmente o fato de vivermos, hoje, em uma sociedade de produção e de consumo em massa, relações entre produtores, comerciantes e prestadores de serviços, em um pólo, e compradores e usuários dos serviços, no outro.

E não há que se falar sequer em caso fortuito ou força maior, pois estas são excludentes da responsabilidade civil subjetiva. Logo, alienígena à relação de consumo, pois, não há discussão de culpa, uma vez que a responsabilidade objetiva independe da aferição de culpa.

E, de acordo com o nosso entendimento, a aplicação é extensiva ao site de compra coletiva. E de mesma sorte tem-se a responsabilidade objetiva desse site ao infringir o artigo 20 da Lei n. 8.884/94 com o abuso do poder econômico e prática de concorrência desleal.

\section{Considerações finais}

É possível verificar que a compra coletiva não produz problemas apenas aos consumidores, como, também, aos fornecedores. Resta saber até quando essa modalidade de venda perdurará na realidade jurídica, pois a somatória de ações contra os sites de compra coletiva podem, muito em breve, inviabilizar sua existência.

O fato é que a matéria ainda é nova, tanto no âmbito do CDC quanto em termos de concorrência. Uma vez nesta seara, o comum é se tratar de casos em que o preço subiu por abuso de poder econômico, porém, ainda não em casos de baixa do preço por compra coletiva.

De tal sorte que se o Direito Digital e Eletrônico ainda possui uma vasta lacuna normativa, o que dizer do direito concorrencial às avessas. Contudo, nada obsta a sua responsabilização, seja por danos ao mercado e aos demais fornecedores seja por danos aos consumidores. 


\section{Referências}

BRASIL. Presidência da República. Lei n 8.884, de 11 de junho de 1994. Transforma o Conselho Administrativo de Defesa Econômica (CADE) em Autarquia, dispõe sobre a prevenção e a repressão às infrações contra a ordem econômica e dá outras providências. Diário Oficial [da] República Federativa do Brasil, Poder Legislativo, Brasília, DF, 11 jun. 1994. Disponível em: 〈http://www.planalto.gov.br/ccivil_03/leis/L8884.htm>. Acesso em: 20 jul. 2010.

DIAS, J. L. P. de O.; PRADO, P. P. P. Responsabilidade civil objetiva no Código de Defesa do Consumidor: um outro ponto de vista. In: NERY Jr., N.; NERY, R. M. de A. (Org.). Doutrinas essenciais responsabilidade civil. São Paulo: Revista dos Tribunais, 2011, v. IV, p. 402-424.

FINKELSTEIN, M. E. Direito do comércio eletrônico. 2. ed. Rio de Janeiro: Elsevier, 2011.

GONÇALVES, C. R. Responsabilidade civil. 8. ed. São Paulo: Saraiva, 2003.

JORNAL da Tarde. São Paulo, 22 de novembro de 2011. Caderno Seu Bolso. n. 15065. p. 3B.

MARQUES, C. L. Contratos no Código de Defesa do Consumidor: o novo regime das relações contratuais. 5. ed. São Paulo: Revista dos Tribunais, 2005.

NAZAR, N. Direito econômico. 2. ed. Bauru: Edipro, 2009.

NERY Jr., N.; NERY, R. M. A. Código civil comentado. 8. ed. São Paulo: Revista dos Tribunais, 2011.

PINHEIRO, A. C.; SADDI, J. Direito, economia e mercados. Rio de Janeiro: Campus, 2005. 
SAYEG, R. H. Práticas comerciais abusivas: monopólio x consumo; abuso do poder econômico; responsabilidade civil e penal. Bauru: Edipro, 1995.

Recebido: 12/07/2012

Received: 07/12/2012

Aprovado: 26/09/2012

Approved: 09/26/2012 